SILVA, Dinar Souza da; CABRAL, Romilson Marques. Reflexos do acesso e consumo de água potável no cotidiano de mulheres em situação de pobreza: um estudo em comunidades urbanas do município de Jaboatão dos Guararapes/PE. Oikos: Família e Sociedade em Debate, v. 30, n. 1, p. 49-67, 2019.

PPGED

Programa de Pós-Graduação

em Economia Doméstica

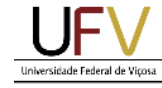

www.periodicos.ufv.br/oikos | ISSN: 2236-8493

Avaliação: Double Blind Review

Recebido: 26/01/2019 Aprovado: $23 / 04 / 2019$

\title{
Reflexos do acesso e consumo de água potável no cotidiano de mulheres em situação de pobreza: um estudo em comunidades urbanas do município de Jaboatão dos Guararapes/PE1
}

\author{
Reflections of access and consumption of drinking water in the daily life of women in \\ poverty situation: a study in urban communities of the city of Jaboatão of the \\ Guararapes/PE
}

\author{
Dinar Souza da Silva² \\ Romilson Marques Cabral ${ }^{3}$
}

\section{Resumo}

Historicamente, as mulheres são as que mais padecem com a falta de acesso à água potável. Quase sempre são atribuições delas as atividades domésticas, incluindo suprir a demanda de água. A divisão sexual do trabalho determina tarefas de homens e mulheres, inclusive dentro do lar. Este artigo apresenta parte da pesquisa de dissertação de mestrado, e tem como objetivo descrever de que forma a falta de acesso à água potável reflete no cotidiano de mulheres em situação de pobreza. A construção desta pesquisa teve uma abordagem qualitativa, exploratória, composta por pesquisa documental, coleta de campo e tratamento dos dados. A pesquisa foi realizada em comunidades da área urbana do município de Jaboatão dos Guararapes/PE. Os resultados apontam que muitas mulheres têm o cotidiano marcado pela precarização do acesso e do consumo de água. A provisão de infraestruturas para um abastecimento de água adequado reduziria potencialmente a sobrecarga de tempo de mulheres, uma vez que, além do período gasto em afazeres domésticos, precisam dedicar um tempo para o provimento de água, aumentando, assim, a sobrecarga total de trabalho.

Palavras-chave: Mulher e aceso à água; Acesso à água e pobreza; Divisão sexual do trabalho; Atividades domésticas.

\begin{abstract}
Historically, the women are the ones that more suffer with the lack of access to drinking water. Domestic activities are almost always attributed to them, including supply of water. The sexual division of labor determines tasks of men and women, also within the home. This article presents part of the research of Dissertation of Master's degree, and has as objective to describe of that it forms the lack of access to safe drinking water reflects in the daily life of the women in poverty situation. The construction of this work had a qualitative approach, exploratory, composed by: documentary research, field collection, and data processing. The research was carried out in communities of the urban area of the municipality of Jaboatão of the Guararapes/PE. The results indicate that many women have a daily life determined for the precarious of access and consumption of water. Provision of infrastructure for an adequate water supply would potentially reduce women's overtime, in addition to the time spent on household chores, they need to devote time to water provision, thus increasing the total workload.
\end{abstract}

Key-words: Women and access to drinking water; Water and gender; Sexual division of labor; Poverty and gender.

\footnotetext{
${ }^{1}$ O presente trabalho foi realizado com apoio da Coordenação de Aperfeiçoamento de Pessoal de Nível Superior - Brasil (Capes).

${ }^{2}$ Mestre em Consumo, Cotidiano e Desenvolvimento Social pela Universidade Federal Rural de Pernambuco, Recife, PE. Residente em Saúde Coletiva com ênfase em Gestão de Redes de Saúde pela Escola de Governo em Saúde Pública de Pernambuco (ESPPE). E-mail: dinarsouzasouza@gmail.com

3 Doutor em Administração pela Universidade Federal da Bahia, Salvador, Bahia. Professor do Programa de Pós-Graduação em Consumo, Cotidiano e Desenvolvimento Social da Universidade Federal Rural de Pernambuco, Recife, PE. romilson.cabral@ufrpe.br
} 


\section{INTRODUÇÃO}

A dificuldade de acesso à água potável não é uma questão rara, principalmente quando se trata de países em desenvolvimento. O não abastecimento de água por redes distribuidoras contribui para um consumo fora dos padrões de potabilidade. A problemática em questão pode ser ocasionada por diversos fatores, passando por questões, econômicas, políticas, sociais, culturais e, em algumas regiões, por fatores naturais.

É preciso ressaltar que, em geral, esse fenômeno não acontece em todas as camadas sociais. Em tese, a problemática do não acesso à água ou do acesso precário se perpetua em áreas nas quais se encontram atores sociais em situação de pobreza, em que perpassam deficiências de planejamento, infraestrutura e de serviços básicos. De modo geral, são aqueles que também apresentam carências em outras dimensões da vida, principalmente de moradia e de renda.

Percebe-se um impacto desigual, em que pobres, crianças e mulheres são os mais prejudicados/as (UNESCO, 2015), sendo o abastecimento de água - como um problema social mais habitual em comunidades formadas por sujeitos de menor poder aquisitivo, afetando de forma mais acentuada mulheres. Algumas produções como as de Costa et al. (2009); Zinato (2008); Hora et al. (2012) apontam que a mulher fica sempre mais exposta às problemáticas causadas pelo não acesso à água. A problemática da falta de água afeta as mulheres de tal modo que o tema já foi levado para espaços públicos, como a Marcha das Mulheres de São Paulo, no ano de 2015.

Comumente, é de competência da mulher o provimento e o gerenciamento da água dentro do lar para o uso coletivo do recurso. A importância que a figura feminina carrega dentro está atrelada à forma como se organizam as sociedades, com a divisão de papéis de cada ator social. Soma-se a essa divisão de papéis a divisão social do trabalho. Segundo Hirata e Kergoat (2007), a divisão sexual do trabalho é fruto da divisão social estabelecida nas relações sociais entre os sexos. Historicamente, as relações sociais entre os sexos se dão de forma hierarquizada e até mesmo opressiva.

No que concerne o suprimento de água nas famílias em situação de pobreza, a mulher tem um papel fundamental, uma vez que, nas mais diversas culturas, a mulheres ficam responsáveis pelo uso e pela gerência de recursos de água, de saneamento e de saúde no nível doméstico. Quando há obstáculos para o acesso de água de forma regular e adequada, 
procuram-se alternativas para garantir esse acesso e, quase sempre, esse trabalho é desenvolvido por mulheres.

É comum associar os problemas da falta do acesso à água às áreas rurais, entretanto esse fenômeno também perpassa por áreas urbanas e, mesmo em contextos distintos, 0 cotidiano de mulheres é afetado quase que na mesma intensidade. Como argumenta Hora et al. (2012), a ausência de saneamento e de ações voltadas para o tratamento das águas, bem como para melhoria do acesso, contribui para agravar a situação de vulnerabilidade social em que muitas mulheres se encontram, principalmente, aquelas localizadas nas periferias urbanas, comunidades rurais ou assentamentos precários.

Diante do exposto, o presente trabalho tem por objetivo descrever de que forma a falta de acesso à água potável se reflete no cotidiano de mulheres em situação de pobreza. Embora seja um direito humano, problemas relacionados ao acesso e ao abastecimento de água têm afetado parte da sociedade e, nesse contexto, é necessário pensar como tais problemas incidem no dia a dia de mulheres, já que, habitualmente, são elas quem provêm e gerenciam o uso coletivo de água dentro do lar.

\section{DIVISÃO SEXUAL DO TRABALHO: O ACESSO À ÁGUA E O COTIDIANO FEMININO}

Desde o final do século XIX, contesta-se a teoria determinista, que usava a biologia para explicar a inferiorização do sexo feminino e as desigualdades sociais entre os gêneros. Ao longo da história, é possível notar uma evidente divisão entre domínio público e privado, em que os homens estavam sempre para a esfera pública e as mulheres, para a esfera privada. Enquanto o homem desempenhava de forma predominante o papel de provedor da família, a vida cotidiana da mulher era dedicada a cuidar do lar.

A vida cotidiana apresenta formas específicas em cada momento histórico, bem como em cada sociedade. Pode-se afirmar que o dia a dia da mulher é definido a partir do contexto no qual está inserida. Sobre o cotidiano, Lefebvre (1968) argumenta que esse é uma forma de identificar a sociedade em que estamos inseridos, de modo que essa sociedade gera a cotidianidade. A partir da cotidianidade é possível organizar os fatos que acontecem na sociedade. Certeau (1994) analisou as práticas cotidianas como modos de ação, nas quais essas aparecem como fatores determinantes para a interação social.

Cotidianamente, na maioria dos lares ainda é de competência da mulher o serviço doméstico, é de responsabilidade dela prover água potável para as atividades do lar. 
O espaço doméstico está sendo considerado aqui como a "casa", na perspectiva de Sarti (1994), que é onde se projeta ter uma família. Nesse contexto, há uma diferença de autoridade em que a casa é identificada por meio da mulher e a família, pelo homem, de modo que a hierarquia se configura a partir do momento no qual a casa está contida na família. O homem corporifica a identidade moral da respeitabilidade familiar e a mulher zela pelo bem-estar, vinculado à "valorização" materna.

Apesar de haver mudanças no cotidiano do lar, as famílias ainda conservam pontos que reforçam a 'naturalização' do trabalho doméstico ligado à mulher. Em relação a isso, Silva (1998, p. 38) destaca que "o padrão de relações de gênero onde a mulher serve e o homem provê é muito mais extensivo socialmente e é a força ideológica preponderante, mesmo onde a mulher também provê". Aludindo ao que argumentou Hartmann (1980), a subordinação das mulheres é produto de determinadas formas de organização e funcionamento das sociedades. Engels (2000) enfatiza que a subordinação da mulher ao homem se deu com a origem da propriedade privada, como forma de organizar o ambiente familiar. Para Hirata e Kergoat (2007, p. 599), a divisão sexual do trabalho "é a forma de divisão do trabalho social decorrente das relações sociais entre os sexos; mais do que isso, é um fator prioritário para a sobrevivência da relação social entre os sexos. Essa forma é modulada histórica e socialmente".

A divisão sexual do trabalho aqui abordada - com as mulheres responsáveis pelo abastecimento de água - não diz respeito à distribuição diferencial de homens e mulheres no mercado de trabalho, nos ofícios e nas profissões, nem as variações no tempo e no espaço dessa distribuição, mas sim à divisão desigual do trabalho doméstico entre os sexos.

Tomando como base o modelo tradicional de família, ou a família nuclear ${ }^{4}$ - aquelas formadas a partir da relação homem-mulher - o papel na família e papel doméstico são assumidos inteiramente pelas mulheres e o papel de "provedor" é atribuído aos homens (HIRATA; KERGOAT, 2007). Mesmo quando crianças, muitas meninas já são orientadas e estimuladas a desenvolver atividades impostas pela sociedade patriarcal como "serviços de mulher".

A divisão sexual do trabalho entre os homens e mulheres é em primeiro lugar a imputação aos homens do trabalho produtivo - e a dispensa do trabalho doméstico - e a atribuição do trabalho doméstico às mulheres, ao passo que são cada vez mais numerosas na nossa sociedade salarial as mulheres a querer entrar e se manter no mercado de trabalho.

${ }^{4}$ Não desconsiderado as outras formações e arranjos familiares. 
Quanto a nós, a simples utilização de termos como "trabalho doméstico" mostra que nos situamos na sociedade salarial. (HIRATA, KERGOAT, 2003, p.113)

Segundo Woolf (2004), a mulher precisa buscar seu espaço e ser protagonista da sua história, uma vez que, historicamente, esteve sujeita à exclusão na sociedade, devendo desconstruir essa ideia de que o homem é o sujeito singular da história.

Foi com a tomada de consciência de uma "opressão" específica que teve início o movimento das mulheres: torna-se então coletivamente "evidente" que uma enorme massa de trabalho é efetuada gratuitamente pelas mulheres, que esse trabalho é invisível, que é realizado não para elas mesmas, mas para outros, e sempre em nome da natureza, do amor e do dever materno (HIRATA; KERGOAT, 2007, p. 597).

$\mathrm{Na}$ busca por protagonizar a própria história, alguns papéis sociais acabam sendo modificados, como a inserção da mulher no mercado de trabalho, no qual, além de desempenhar o papel de trabalhadora fora do lar, continua cumprindo as atividades no âmbito do lar. Quando isso acontece, o cotidiano da mulher é dividido entre o público e o privado.

A sociedade patriarcal "reservou" às mulheres o papel de cuidar, de servir. Até mesmo nos postos de trabalho que ocupam, muitas profissões ainda são majoritariamente desempenhadas por mulheres, tais como babá, doméstica, professoras do ensino fundamental (incluindo os primeiros anos escolar), agente comunitário de saúde, cozinheira, dentre outras (MINISTÉRIO DO TRABALHO E EMPREGO, 2016). Socialmente, existe uma naturalização da atribuição do trabalho doméstico à mulher e o não reconhecimento desse como trabalho.

\section{ABASTECIMENTO DE ÁGUA PRECÁRIO: OS REFLEXOS NO SERVIÇO DOMÉSTICO}

De modo a prover água para a manutenção do lar, é preciso ter acesso à ela, todavia, em se tratando do acesso ao recurso, persistem ainda desigualdades ocasionadas por diversos fatores, dentre tais, fatores econômicos e políticos.

A essencialidade da água se dá não apenas para manter o corpo físico, mas também para as mais diversas atividades, sejam elas domésticas, industriais, agrícolas, culturais, dentre outras. Dessa forma, esse elemento possui uma pluralidade de características socioculturais que se manifestam por meio de sentidos e normas de uso os quais se modificam conforme os padrões das sociedades e culturas.

Caracterizando-se como um bem de consumo coletivo, necessário a todos em qualquer esfera social, a água é também dotada de valor econômico e social. Como bens de consumo coletivo, Bernado Sorj (2003) argumenta que 
são aqueles cujo acesso a sociedade, em cada momento histórico, considera ser condição de cidadania; e, por isso, não podem ser abandonados à lógica distributiva do mercado exigindo, portanto, a intervenção pública. Sob a ação pública, os bens coletivos podem perder a qualidade de bem mercantil ou, em certas circunstâncias, eles podem ser produzidos e/ou distribuídos pelo mercado, mas sob controle ou supervisão do poder público. Em todos esses casos, o Estado deve intervir, seja orientando os investimentos, seja subsidiando ou controlando os preços, de forma a assegurar o acesso universal aos bens de consumo coletivo, independente da renda individual (SORJ, 2003, p. 32).

Para atender às necessidades mais básicas, a Organização Mundial da Saúde (OMS) recomenda, diariamente, o consumo de cerca de 50 a 100 litros de água por pessoa.

Em 28 de julho de 2010, a Assembleia Geral das Nações Unidas, por meio da Resolução A/RES/64/292, declarou a água limpa e segura, bem como o saneamento, um direito humano essencial para gozar plenamente a vida e todos os outros direitos humanos (ONU, 2010).

Marcados por grande desigualdade social, com forte concentração de renda, muitos países - inclusive o Brasil - ainda estão longe de garantir às populações pauperizadas o acesso e, consequentemente, o consumo de água como um direito humano. A forma como se dá o acesso e o consumo da água em diversas partes do mundo pode contribuir para um quadro de exclusão social.

As dificuldades no tocante ao acesso à água potável e, por conseguinte, ao seu consumo seguro faz com que mulheres encontrem soluções inseguras com relação à água, 0 que compromete a subsistência delas, culminando em uma feminização da pobreza (D'ÁVILA NETO; JARDIM, 2015).

Tal como escreveram D’Ávila Neto e Jardim (2015), a vulnerabilidade feminina é consequência não apenas de condições de pobreza e de status econômico da família, mas também de barreiras socioculturais que impedem sua participação nas sociedades. Os autores citam que uma das vulnerabilidades as quais as mulheres estão expostas é a escassez da água, consequente de desastres ecológicos, condições sazonais regionais ou simplesmente questões de ordem política e econômica, de modo que as agências internacionais vêm buscando a inclusão da dimensão de gênero no que tange às políticas hídricas para o desenvolvimento.

Uma questão relevante que deve ser levada em conta com relação às mulheres é o gerenciamento dos usos da água em âmbito doméstico, quais sejam, as responsabilidades que recaem sobre elas de terem que administrar os recursos envolvendo a vida doméstica e que resultam em uma série de interações cotidianas com o meio ambiente.

A participação feminina, nos últimos anos, também está sendo levada para fora do lar (TORRES, 2005). Empenhadas em compensar a insuficiência crônica de serviços e equipamentos sociais e coletivos - entre tais o abastecimento de água potável - produzem um 
volume considerável de trabalho cotidiano "gratuito", trazendo à ordem do dia a importância das políticas públicas que incorporem suas necessidades e sua participação nas tomadas de decisões (CALIÓ; ROSSINI, 2005). Apesar de a participação da mulher ser notória no tocante a suprir a casa com água potável para o uso coletivo, temos como um contraponto a tomada de decisões sobre os serviços de abastecimento.

Se em muitos países, grande quantidade de trabalho relacionado à água é fornecida pelas mulheres, que pouco ou quase nada recebem por ele, não há dúvida de que o direito de acesso à água, à terra irrigada, à infraestrutura e às tecnologias hidráulicas, e o poder de decisão sobre estes direitos são, predominantemente, atribuídos aos homens (CALIÓ; ROSSINI, 2005, p. 121).

Importa ressaltar que, nos países em desenvolvimento, o tempo dedicado aos afazeres domésticos pelas mulheres contribui para a perda de renda. Contabiliza-se, por exemplo, o tempo gasto em buscar, carregar e purificar água, momentos que poderiam ser trocados por atividades que gerem renda, atividades de lazer ou busca por instrução pessoal. Assim, as mulheres ficam sobrecarregadas com atribuições que não thes garantem nenhuma remuneração, enquanto que os homens realizam atividades geradoras de renda (COSTA et al., 2009).

O acesso e o consumo de forma precária contribuem para uma série de questões que podem impactar negativamente a vida das mulheres. Podem-se destacar os malefícios para 0 próprio corpo físico, como desidratação e doenças. Estudos apontam que as doenças transmitidas pela água poluída e pelo saneamento deficitário são a quinta maior causa de morte de mulheres no mundo, fazendo mais vítimas que a AIDS, o diabetes ou o câncer de mama. As únicas doenças mais mortíferas para as mulheres do que a falta de água e saneamento de qualidade são doenças cardíacas, derrames, infecções das vias respiratórias inferiores e doenças pulmonares obstrutivas crônicas (CLOROSUR, 2016).

Por ano, quase 800 mil mulheres morrem por falta de acesso a banheiros seguros e à água (CLOROSUR, 2016).

Além das questões de saúde descritos, outros problemas que também vitimizam as mulheres são problemas na coluna, muitas vezes por terem que transportar água em baldes ou latas pesadas por longa distâncias, subindo e descendo ladeiras e escadarias; mau rendimento no emprego, por terem que acordar pela madrugada para apanhar água, uma vez que, em muitas comunidades, a água só se encontra disponível pela rede pública nesse período.

Outra questão que coloca as mulheres em maior vulnerabilidade é a exposição que enfrentam quando precisam captar água em fontes distantes de suas residências, o que as deixa 
vulneráveis a situações de violência. Segundo a ACNUR (2011), muitas mulheres e meninas que vivem em diversas partes do mundo, incluindo o Brasil, correm o risco de sofrerem violência sexual ou algum outro tipo de violência quando buscam água ou quaisquer outros recursos essenciais por não os terem disponíveis no lar.

Aqui no Brasil, em muitas comunidades, mulheres fazem um percurso considerável na busca de captar água para a manutenção da casa. Costa et al. (2009) afirmam, ainda, que a infraestrutura de água está interligada à menor sobrecarga de trabalho para as mulheres, já que essas não teriam que se deslocar para adquirirem esse recurso natural.

O abastecimento de água de uso doméstico se configura como um dos fatores mais importantes para a manutenção da saúde familiar e da dignidade social, bem como para a geração de oportunidades de sustento, renda e contribuição para produtividade econômica. O investimento na gestão de recursos hídricos e nos serviços associados a ele contribui para a redução da pobreza e se determina como suporte para o desenvolvimento econômico.

\section{PROCEDIMENTOS METODOLÓGICOS}

Os dados utilizados para este artigo são os mesmos utilizados na pesquisa da dissertação de mestrado que o originou e foram analisados a partir do método quantitativo. $O$ método quantitativo se caracteriza pelo emprego da quantificação tanto nas modalidades de coleta de informações quanto no tratamento delas por meio de técnicas estatísticas, desde as mais simples até as mais complexas (RICHARDSON, 2002).

Quanto ao objetivo da pesquisa, essa pode ser considerada exploratória. A pesquisa exploratória possibilita a sondagem e permite chegar ao conhecimento mais profundo de algumas questões. De acordo com Silveira e Córdova (2009), a pesquisa exploratória proporciona maior familiaridade com o problema, com vistas a torná-lo mais explícito ou a construir hipóteses.

Inicialmente, foi realizada uma pesquisa bibliográfica, sendo esse um passo preliminar essencial em cada projeto de pesquisa (CERVO; BERVIAN, 1996). A legitimidade dessa opção metodológica também é confirmada por (BECKER, 1993), quando afirma que a revisão da literatura antes da coleta de dados de campo procura explicar um problema a partir das referências teóricas publicadas em documentos, resultando como base importante do trabalho para complementar uma pesquisa empírica.

Posteriormente, foi realizada uma pesquisa de campo, com entrevista semiestruturada. A 
presente pesquisa se deu em duas comunidades urbanas do município de Jaboatão dos Guararapes, localizado na Região Metropolitana do Recife (RMR), Pernambuco. Nessa região do Estado predomina certa abundância de precipitações hídricas, não sendo comum a escassez de chuvas, se consideradas outras regiões do mesmo Estado. A Barragem do Pirapama, por exemplo - que compõe o Sistema Pirapama -, localizada no Cabo de Santo Agostinho, Região Metropolitana do Recife, tem capacidade de acumular 61 milhões de metros cúbicos. O Sistema Pirapama é o maior sistema de abastecimento de água de Pernambuco e um dos maiores do Brasil (COMPESA, 2014).

O público-alvo para a aplicação da pesquisa foram moradores das comunidades de Campo do Flamengo e Vila Nestlé, entretanto, para a construção do presente trabalho, foi feito um recorte de gênero. Durante a coleta de dados, foi possível observar que as mulheres apareciam como atores centrais no tocante ao abastecimento de água no lar, consequentemente apresentando maiores problemas com relação à falta de água, assim como uma maior vulnerabilidade à problemática.

A pesquisa de campo foi realizada em janeiro de 2018. No total foram aplicadas 100 entrevistas semiestruturadas em 69 mulheres e 31 homens. Para este trabalho, foram utilizadas as entrevistas aplicadas às mulheres. A seleção dos/as entrevistados/as foi realizada por ordem aleatória, a partir de uma amostra não probabilística, por acessibilidade e tipicidade.

O terceiro e último passo foi a análise dos dados obtidos a partir da pesquisa de campo. Os dados foram analisados e interpretados, procurando-se angariar uma diversidade de informações, de forma a trazer subsídios que pudessem auxiliar da realidade que pretendíamos conhecer. Para interpretação dos dados foram aplicadas as técnicas da análise de conteúdo, visando obter, por procedimentos sistemáticos e objetivos de descrição do conteúdo das mensagens, indicadores que permitiram a inferência de conhecimentos relativos às condições de produção ou recepção dessas mensagens (BARDIN, 2009).

Dentro da análise de conteúdo, foi utilizada a técnica de análise temática. Segundo Minayo (2007, p. 36), "a análise temática consiste em descobrir os núcleos de sentido que compõem uma comunicação cuja presença ou frequência signifique alguma coisa para o objetivo analítico visado".

A análise dos dados foi realizada a partir dos dados quantitativos, que permitiram traçar o perfil socioeconômico das famílias entrevistadas; no segundo momento, os dados quantitativos contribuíram para traçar a caracterização do abastecimento de água nas duas comunidades. Por fim formularam-se categorias, de acordo com o objetivo de cada questão. Nas análises dos 
dados, algumas categorias vão aparecer com um pequeno percentual, entretanto, nessas análises não será levado em conta apenas o grau de frequência em que aparecem, mas sim como se apresentam no cotidiano dos sujeitos.

\section{RESULTADOS E ANÁLISES}

Como descrito anteriormente, as comunidades de Campo do Flamengo e Vila Nestlé estão situadas no município de Jaboatão dos Guararapes, na área urbana, no bairro de Jardim Jordão. A primeira dispõe de água pelo sistema público - Compesa ${ }^{5}$ - enquanto que a segunda precisa se abastecer de forma autônoma, através de poços artesianos e cacimbas.

A escolha dessas comunidades se deu pela proximidade de ambas, bem como pela total discrepância ao acesso e ao consumo de água potável. As duas comunidades estão localizadas em uma área cercada por repartições públicas, indústrias e comércios.

Estima-se que as comunidades tenham, juntas, aproximadamente 350 famílias, sendo que Campo do Flamengo tem aproximadamente 150 famílias e já Vila Nestlé, aproximadamente 200. É possível perceber que existem poucos investimentos nessas comunidades, em virtude de suas precárias infraestruturas. As ruas não são asfaltadas, muitos trechos têm pouca ou nenhuma iluminação. Segundo os moradores, a coleta de lixo na comunidade de Vila Nestlé é diária, enquanto que, na comunidade de Campo do Flamengo, acontece a cada três dias. Em ambas o sistema de esgotamento sanitário é inexistente, de modo que, em vários trechos das ruas, encontram-se esgotos a céu aberto.

Observa-se a inexistência de equipamentos coletivos em ambas as comunidades, como escolas e Estratégias de Saúde da Família (ESF), por exemplo, sendo necessário que os moradores façam uso desses equipamentos em comunidades circunvizinhas.

Nas referidas comunidades, observa-se uma concentração de famílias em situação de pobreza. Esse fator pode contribuir para a falta de investimentos e estruturas, dentre tais, a disponibilidade de água pelo sistema público, resultando em um abastecimento e um consumo de água precários para seus habitantes.

Chama atenção o fato de as duas comunidades abrigarem um dos maiores reservatórios de água tratada do Estado, o Reservatório do Jordão, uma das composições do Sistema Pirapama, tendo capacidade para acumular 90 mil metros cúbicos de água.

${ }^{5}$ Companhia Pernambucana de Saneamento. 
Esse paradoxo leva ao total descontentamento da população em volta que, apesar de se localizar às margens de um grande volume de água potável, sofre com sua ausência ou com a precariedade no seu fornecimento.

Das 69 mulheres entrevistadas, 42,0\% afirmaram ser chefe de família. Vale ressaltar que algumas entrevistadas estavam no papel de provedoras da família, por motivo de desemprego do companheiro, entretanto, elas não se consideravam chefes de família.

O papel fundamental da mulher na casa dá-se, portanto, dentro de uma estrutura familiar onde o homem é essencial para a própria concepção do que é família, por que a família é pensada como ordem moral, onde o homem representa a autoridade. Mesmo quando ele não provê a família, sua presença 'desnecessária', continua necessária (SARTI, 1994, p. 89).

Segundo Ferreira (1986), "provedor" é aquele que provê; e o "prover" não se resume à provisão econômico-financeira, prover se estende aos cuidados e afetos. No entanto, embora algumas mulheres estivessem como a única provisão dos recursos financeiros da casa, nem todas se sentiam como tal. "Por mais que eu traga o dinheiro pra dentro de casa, coloque a comida e pague as contas, o chefe é o homem, pra mim é..." (ENTREVISTADA 37, CAMPO DO FLAMENGO).

Com relação ao grau de escolaridade, percebe-se certa deficiência no tocante à educação ${ }^{6}$, principalmente quando se trata das séries do ensino médio e de acesso ao superior, em que a maior parte das mulheres entrevistadas alegaram ter estudado apenas as séries do ensino fundamental - completo ou incompleto - como pode ser observado na Tabela 1.

\footnotetext{
${ }^{6} \mathrm{Na}$ ocasião, não foi questionado a causa de a entrevistada ter estudado até determinada série, ou, em alguns casos, o porquê dos entrevistados não terem frequentado escola em algum momento da vida, entretanto, alguns estudos revelam que, quanto maior a vulnerabilidade social do território, menor o nível da qualidade de ensino ofertado e menor a aprendizagem dos alunos, aumentando, também, a evasão escolar, dinâmica denominada 'Efeito do Território'. De acordo o estudo 'Educação em territórios de alta vulnerabilidade social na metrópole", realizado pela Cenpec, em parceria com a Unicef Brasil, enfatiza que "a hipótese existente [...] está relacionada ao fenômeno da segregação socioespacial nas metrópoles, especialmente à concentração de suas populações mais pobres em regiões marcadas pelo isolamento e pelas dificuldades de acesso a bens e serviços" (CENPEC, 2011).
} 
Tabela 1 - Percentual do nível de escolaridade das entrevistadas, Jaboatão, 2018

\begin{tabular}{|c|c|c|c|}
\hline \multirow[t]{2}{*}{ Escolaridade } & \multicolumn{2}{|c|}{ Comunidade } & \multirow[t]{2}{*}{ Total } \\
\hline & Campo do Flamengo (\%) & Vila Nestlé (\%) & \\
\hline Não alfabetizado & 4,3 & 5,8 & 10,1 \\
\hline Ens. Fundamental & 29,0 & 43,5 & 72,5 \\
\hline Ens. Médio & 7,3 & 8,7 & 16,0 \\
\hline Ens. Superior & 1,4 & 0 & 1,4 \\
\hline Total & 42,0 & 58,0 & 100 \\
\hline
\end{tabular}

Fonte: Elaboração própria (2018).

Observa-se que o acesso ao ensino superior é quase inexistente, sendo que apenas 1,4\% das entrevistadas o possui. O grau de escolaridade delas se reflete nas atividades que desenvolvem. Com os indivíduos vivendo majoritariamente em situação de pobreza, as ocupações que aparecem com mais frequência são as de prestadoras de serviços, como auxiliar de serviços gerais e domésticos; seguidas por trabalhadores autônomos (como, por exemplo, pequeno comércio).

É necessário salientar que uma parcela significativa das entrevistadas encontrava-se em situação de desemprego, sobrevivendo de trabalhos informais e não fixos. Algumas famílias têm como única fonte de renda benefícios do Governo, sendo o mais comum o Programa Bolsa Família (PBF). Em geral, a soma da renda familiar não ultrapassa 1,5 salário mínimo.

Com base nos descritos acima, é possível afirmar que ambas as comunidades são formadas quase que prioritariamente por indivíduos que vivem em situação de pobreza - dentre esses, as mulheres entrevistadas nesta pesquisa. Essas pessoas apresentando baixa escolaridade e postos de trabalhos precários, uma vez que a pobreza está profundamente relacionada ao modo e às mutações na estrutura ocupacional, refletindo, assim, a qualidade do posto de trabalho que os sujeitos pobres ocupam.

As ocupações/postos de trabalho dos indivíduos determinam a renda familiar, o que por ser uma renda baixa, limita o acesso a muitos bens de consumo, inclusive, o acesso à água potável. Vivendo em uma área desprovida de investimentos e infraestrutura, não raramente seus habitantes sentem falta de acesso a equipamentos essenciais para a vida em sociedade.

Quando indagadas sobre os principais problemas relacionados ao abastecimento de água, 20,3\% alegaram ter as atividades domésticas prejudicadas. Sobre isso, as entrevistadas de Campo do Flamengo relataram que, devido ao fato de os serviços de abastecimento de água (sistema público) não serem repassados de forma regular, com dias e horários certos, bem como em períodos adequados para sua captação - já que, por vezes, a água fica disponível nas torneiras no período noturno ou até mesmo pela madrugada, cessando o abastecimento durante 
o dia -, as atividades no âmbito do lar são acumuladas, principalmente quando se trata da higiene.

As moradoras de Vila Nestlé que não dispõem de um poço artesiano em casa pagam uma taxa a algum vizinho/a que o tenha, para, assim, ter acesso a água. Importa ressaltar que essa comunidade não é contemplada com redes distribuidoras de água, ou seja, não é servida de água pelo sistema público.

As moradoras de Vila Nestlé precisam esperar os dias determinados pelos proprietários dos poços para captar água. Alguns repassam água de dois em dois dias, outros de três em três dias, a depender da quantidade de famílias que cada poço (privado) abastece.

A gente precisa de água todo dia NE? Mas ai o dono do poço diz que só pode pegar de três em três dias, porque têm mais gente pra pegar. O ruim é que lá em casa só tem um reservatório pra tudo, tem que economizar muito pra não acabar antes do tempo, até o banho é limitado por conta disso, não tem como ninguém tomar três banhos por dia, de jeito nenhum, nem mesmo nas crianças eu dou. Como a gente não tem água da Compesa, tem que se sujeitar a isso mesmo. (ENTREVISTADA 33, VILA NESTLÉ)

Além do mais, as moradoras de Vila Nestlé precisam se deslocar de suas casas para captarem água, dispensando parte do tempo para realizar essa atividade.

Toda vez é isso, a gente tem um monte de prato, roupa pra lavar, mas primeiro eu tenho que dá de seis a sete viagens lá no poço com minha menina mais velha, pra pegar água e começar a lavar roupa e prato. Às vezes eu começo a lavar e ela continua pegando água sozinha, pra abastecer o reservatório aqui de casa pra usar nas outras coisas. Fico acumulando serviço em casa porque sem água ninguém faz nada. (ENTREVISTADA 61, VILA NESTLÉ)

Adentrando agora a questão dos transtornos ocasionados fora do ambiente familiar pela falta de água para a população, foram formuladas três categorias analíticas, expostas com seus percentuais na Tabela 2.

Tabela 2 - Percentual de problemas fora do ambiente familiar, relacionado ao abastecimento de água, Jaboatão, 2018

\begin{tabular}{l|r|r|c}
\multicolumn{1}{c|}{ Categoria } & \multicolumn{2}{|c|}{ Comunidade } & \\
\cline { 2 - 4 } & $\begin{array}{c}\text { Campo do Flamengo } \\
\%\end{array}$ & $\begin{array}{c}\text { Vila } \\
\text { Nestlé } \\
\%\end{array}$ & Total \\
\hline $\begin{array}{l}\text { Mau desempenho no trabalho relacionado à } \\
\text { disponibilidade de água durante a madrugada }\end{array}$ & 19,0 & 13,0 & 32,0 \\
\hline $\begin{array}{l}\text { Comprometimento de equipamentos coletivos na } \\
\text { comunidade }\end{array}$ & 13,0 & 17,4 & 30,4 \\
\hline Não relatou problemas ou não respondeu. & 13,0 & 24,6 & 37,6 \\
\hline
\end{tabular}

Fonte: Elaboração própria (2018). 
Com relação à questão categoria 1. Mau desempenho no trabalho relacionado à disponibilidade de água durante a madrugada, 32\% das entrevistadas afirmou já ter tido problemas fora do ambiente familiar por conta do não abastecimento de água. Por exemplo, o caso do filho voltar da escola e não ter água na comunidade; ir para o trabalho com sono por apanhar água durante a madrugada; etc. A captação de água no período noturno, feita por homens ou por mulheres, acarreta dificuldades nas atividades que esses sujeitos desempenham no ambiente de trabalho fora da residência.

Com relação à categoria 2, Comprometimento de equipamentos coletivos na comunidade, esse número chega a um total de $30,4 \%$ das respostas. A explicação para isso é que os equipamentos em questão são escolas e postos de saúde, onde, no geral, são as mulheres que levam ou despacham as crianças para as escolas, assim como são as que mais frequentam os postos de saúde. Ressalta-se que esses equipamentos coletivos estão em comunidades próximas, também são afetadas pelo abastecimento irregular de água. A perda de aulas por falta de água nas escolas está muito presente na fala das entrevistadas.

[...] hoje mesmo meus dois meninos cada um levou uma garrafa pet de dois litros com água pra beber, pra não passar sede, mas ai na escola não tem como fazer a merenda e nem limpar, vão largar tudo mais cedo, ai eu vou ter que buscar agora de dez horas da manhã, mal cheguei e já vou voltar pra buscar. (ENTREVISTADA 25, VILA NESTLÉ)

Nos dias em que falta água, muitas crianças e adolescentes estudam apenas meio turno, voltando para casa mais cedo. A falta de água nas escolas compromete não só a higiene do local, mas também, em muitas dessas, as refeições servidas, como vimos na fala da moradora acima.

Essa situação não é um caso vivenciado apenas por essas comunidades, uma vez que, mundialmente, pelo menos "443 milhões de dias de aulas são perdidos todos os anos devido a doenças relacionadas com a água" (PNUD, 2006, p.15). Com os horários de aulas reduzidos, muitas mães têm suas atividades domésticas comprometidas, já que o intervalo de buscar novamente as crianças na escola também fica menor quando há ausência de água para consumo.

O consumo de água no ambiente doméstico liga-se também a questões de hábitos e costumes arraigados em cada sociedade, bem como em cada camada social. Grande parte das atividades domésticas, principalmente as ligadas à higiene do lar, dependem exclusivamente da disponibilidade de água em casa. Quando falta, as mulheres se mostram muito mais apreensivas 
que os homens, já que, quase sempre, são elas quem desempenham as atividades do lar, e a falta de água compromete sua manutenção.

\begin{abstract}
Homem não liga muito se tem água ou não, se tiver um balde cheio pra ele tomar banho... quem liga é a gente (mulher) que tem que fazer as coisas, deixar tudo limpo, fazer comida, e se não tiver água, como é que faz? Eu mesma fico doidinha quando essa água não chega (distribuída pela Compesa, agora mesmo você tá vendo todo mundo reclamando, faz uma semana que não chega água, você não acha que isso é mtivo pra gente se preocupar? Porque quando falta ssim, a gente tem que ir comprar ao dono do poço ali em baixo, e ainda caregar peso pra trazer no carro de mão, ai tem que ficar controlando todo mundo dentro de casa, pra não gastar mesmo (ENTREVISTADA 18, CAMPO DO FLAMENGO).
\end{abstract}

Assim, as mulheres terminam desempenhando um papel importante na gestão da água no ambiente doméstico.

Com relação à figura responsável por suprir a casa com água, observou-se que essa é uma atribuição predominante da mulher. O trabalho do homem é considerado suplementar e ocasional na hipótese do desemprego, por exemplo.

Nos casos em que a água não precisa ser conduzida do local de captação para um reservatório doméstico, por exemplo, o controle do suprimento pode ser feito por todos, no entanto, na maioria dos casos esse controle continua a ser atribuição da mulher. Um pequeno percentual afirmou que recebe ajuda do companheiro para suprir a casa com água, mas, ainda assim, temos o trabalho da figura feminina, uma vez que o trabalho do homem aparece como complementar ao da mulher, e não como integral. Desse modo, na maior parte dos lares entrevistados, fica a cargo da mulher prover água para o consumo de todos na casa, não só de suprir, mas também de desempenhar outras atividades que dependem do seu uso.

Percebe-se que o banho e a lavagem de roupa e louças, que em geral, são realizadas de duas a três vezes ao dia (com exceção da lavagem de roupa), representam os maiores gastos de água dentro do lar.

Outra tarefa que requer um grande uso de água é a higienização do banheiro. O uso de água para as descargas e toda a higienização, ao longo do dia, representa um consumo considerável, sendo assim, algumas mulheres alegam reutilizar a água da lavagem da roupa nas descargas do banheiro, a fim de poupar água limpa. Para muitas mulheres, a incerteza do acesso à água acarreta preocupação e as induz a uma economia, muitas vezes forçada e penosa.

Quando pensado em áreas ricas, o volume de água utilizado nas descargas de banheiro quase se equipara ao volume total utilizado por indivíduos em situação de pobreza para a realização de todas as atividades domésticas, em que a maior parte das pessoas com problemas de acesso à água limpa usa cerca de cinco litros por dia, o que equivale a um décimo da 
quantidade média diária utilizada nos países ricos para a descarga dos banheiros, ficando bem abaixo do estipulado pela OMS (PNUD, 2006).

\section{CONSIDERAÇÕES FINAIS}

Enquanto bem de consumo coletivo, a falta de água não só priva os sujeitos apenas de tomar um banho a menos por dia, como também provoca ocorrências que, muitas vezes, são desconhecidas da população em geral. Nota-se tanto uma divisão do trabalho atrelada a questão do gênero bem como uma sobrecarga mais pesada de tempo sobre as mulheres.

Além das questões de saúde, a mulher é afetada quando se pensa em outros contextos referentes à impossibilidade do acesso à água. Voltemos agora a questão das crianças que retornam das escolas e creches mais cedo: muitas mães levam seus filhos à escola e vão para o trabalho. Assim, quando a criança sai da instituição mais cedo, a mãe precisa encontrar alternativas, o que muitas vezes Ihes causa o transtorno de sair do trabalho antes do horário, por exemplo.

Apesar da universalização do acesso aos serviços de saneamento, dentre tais, o abastecimento de água ser um dos princípios fundamentais da Lei de Diretrizes Nacionais de Saneamento Básico, Lei n. 11.445/2007, a universalização dos serviços não é uma realidade próxima para muitas brasileiras. Assim, a possibilidade de todos os brasileiros acessarem os serviços de saneamento, sem qualquer barreira de acessibilidade, seja legal, econômica, física ou cultural, ainda é um desafio a ser alcançado (BRASIL, 2007). Em síntese, quanto melhor for a infraestrutura que permita o acesso à água potável menor será a sobrecarga de trabalho para as mulheres.

Enquanto não forem rompidas as barreiras do acesso e consumo de água potável para a parcela de indivíduos que se encontram desprovidos dela, as mulheres estarão no grupo das mais expostas e, consequentemente, mais vulneráveis a serem afetadas pelas problemáticas decorrentes do acesso precário à água potável.

\section{REFERÊNCIAS}

ACNUR. Alto Comissariado das Nações Unidas para Refugiados. Ação contra a violência sexual e de gênero: uma estratégia atualizada. ACNUR: Divisão de Proteção Internacional, 2011. Disponível em: http://www.acnur.org/fileadmin/scripts/doc.

php?file=fileadmin/Documentos/portugues/Publicacoes/2012/Acao_contra_a_ violencia_sexual_e_de_genero. Acesso em: 01 abr. 2019. 
BARDIN, Laurence. Análise de Conteúdo. Lisboa, Portugal; Edições 70, LDA, 2009.

BECKER, Howard S. Método de Pesquisa em Ciências Sociais. São Paulo: Ed. Hucitec,1993.

BRASIL. Lei no 11.445 de 05 de janeiro de 2007. Dispõe sobre o Saneamento Básico no país. Disponível em: https://www.planalto.gov.br/ccivil 03/ ato2007-2010/2007/lei/l11445.htm. Acesso em: 10 dez. 2018.

CALIÓ, Sônia Alves; ROSSINI, Rosa Ester. Gênero e Gestão das Águas: uso, consumo, excesso e falta. In: GEHLEN, V.R.F.; CHAVES, H.L.A.; et al. Territórios em Risco. Recife: Editora UFPE, 2015. p. 120-135.

CENPEC. Centro de Estudos e Pesquisa em Educação, Cultura e Ação Comunitária. Educação em territórios de alta vulnerabilidade social na metrópole. São Paulo: CENPEC. n. 03, p. 01-39, nov, 2011. Disponível em:< https://www.cenpec.org.br/wpcontent/uploads/2015/08/Informe de Pesquisa3a.pdf>

CERTEAU, Michel. A invenção do cotidiano: artes de fazer. Petrópolis: Vozes, 1994.

CERVO, Amado Luiz.; BERVIAN, Pedro Alcino. A Metodologia científica. 4. ed. São Paulo: Makron Books, 1996.

CLOROSUR. Água poluída e falta de saneamento mata mais mulheres do que Aids ou câncer, mostra estudo. Disponível em:

http://www.clorosur.org/aguapoluidaefaltadesaneamentomatamaismulheresdoqueaidsoucancer mostraestudo/. Acesso em: 05 jun. 2018.

COMPESA. COMPANHIA PERNAMBUCANA DE SANEAMENTO. Sistemas de Abastecimento. Recife, PE, 2014. Disponível em: https://servicos.compesa.com.br/abastecimento-de-agua/. Acesso em: 01 abr. 2019.

COSTA, Joana; HAILU, Degol; SILVA, Elydia; TSUKADA, Raquel. Abastecimento de água em Gana Rural: as mulheres se beneficiam? Centro Internacional de Políticas para o Crescimento Inclusivo (CIP-CI). Brasília; 2009.

D’ÁVILA NETO, Maria Inácia; JARDIM, Gabriel de Sena. A fonte que nunca seca: o trabalho cotidiano de mulheres com a água no semiárido. Pesquisas e Práticas Psicossociais, v. 10, n. 1, p. 155-169, jan/jun, 2015. Disponível em:

$<$ http://pepsic.bvsalud.org/scielo.php?script=sci abstract\&pid=S180989082015000100013\&lng=pt\&nrm=iso >. Acesso em: 10 out. 2019.

ENGELS, Friedrich. A Origem da Família, da Propriedade Privada e do Estado. São Paulo: Companhia das Letras, 2000.

FERREIRA, A. B. H. Dicionário da Língua Portuguesa. Rio de Janeiro: Nova Fronteira S.A, 1986. 
HARTMANN, Heidi. Um matrimonio malavenido: hacia una unión más progressiva entre marxismo y feminismo. Zona Abierta, n. 24, p. 01-32, mar/abr, 1980. Disponível em: < https://fcampalans.cat/archivos/papers/88.pdf>. Acesso: 01 set. 2018.

HIRATA, H.; KERGOAT, D. Novas Configurações da Divisão Sexual do Trabalho. Cadernos de Pesquisa, v. 37, n. 132, p. 595-609, set./dez. 2007. Disponível em:<

http://www.scielo.br/pdf/cp/v37n132/a0537132.pdf>. Acesso: 01 set. $2018 . \quad$ scrosseet

HORA, K.; SCALIZE, P.; FURTADO, C.; FERNANDES, L. Gênero e Gestão Integrada dos Recursos Hídricos e Saneamento: aproximações da realidade caboverdiana e brasileira.

Revista Monografias Ambientais - REMOA, v. 14, n 1, jan./abr. p.166-175. Universidade Federal de Santa Maria, 2015. Disponível em:<

https://periodicos.ufsm.br/remoa/article/viewFile/16697/pdf>. 01 set. 2018.

LEFEBVRE, Henri. A vida cotidiana no mundo moderno. Brasil: Editora Ática S.A., 1991 [1968].

MINAYO, Maria Cecília de Souza. O desafio do conhecimento. 10. ed. São Paulo: HUCITEC, 2007.

MINISTÉRIO DO TRABALHO E EMPREGO. Relação Anual de Informações Sociais (Rais). Brasília; 2016.

ONU. Organização das nações Unidas. Declaração para o Dia Mundial da Água. 2010. Disponível em: < http://www.onu.org.br/a-onu-em-acao/a-onu-em-acao/a-onu-e-a-agua/ >. Acesso: 01 set. 2018.

PNUD. PROGRAMA DAS NAÇÕES UNIDAS PARA O DESENVOLVIMENTO. Relatório de Desenvolvimento Humano: A água para lá da escassez - poder, pobreza e a crise mundial da água. Nova lorque, 2006.

RICHARDSON, Roberto Jarry. Pesquisa social: Métodos e técnicas. São Paulo, Atlas, 2002.

SARTI, Cynthia Andersen. A família como espelho: um estudo sobre a moral dos pobres na periferia de São Paulo. 1994. Tese (Doutorado) - Faculdade de Filosofia, Letras e Ciências Humanas, Universidade de São Paulo. São Paulo, 1994.

SILVA, Elizabeth Bortolaia. Tecnologia e vida doméstica nos lares. Cadernos Pagu. n. 10. p. 21-52. 1998. Google

SILVEIRA, Denise Tolfo; CÓRDOVA, Fernanda Peixoto. A pesquisa científica. In: GERHARDT, T. E.; SILVEIRA, D. T. Métodos de Pesquisa. Porto Alegre: Editora da UFRGS, 2009.

SORJ, B. A luta contra a desigualdade na sociedade da informação. Brasília: Unesco, 2003.

TORRES, Iraildes Caldas. As Novas Amazônidas. Manaus: Editora UFAM, 2005. 
UNESCO. ORGANIZAÇÃO DAS NAÇÕES UNIDAS PARA A EDUCAÇÃO, A CIÊNCIA E A CULTURA. Gestão mais sustentável da água é urgente, diz relatório da ONU. 2015.

Disponível em: http://www.unesco.org/new/pt/brasilia/about-this-office/singleview/news/urgent need to manage water more sustainably says un report/\#.VRsMRPzF $f$ e. Acesso em: 20 nov. 2018.

WOOLF, Virgínia. Um teto todo seu. 2. ed. Rio de Janeiro: Nova Fronteira, 2004.

ZINATO, M. C. A mulher na gestão da água. Portal Tratamento de Água. 2008. Disponível em: $<$ https://www.tratamentodeagua.com.br/artigo/a-mulher-na-gestao-da-agua/>. Acesso: $01 \mathrm{abr}$. 2019. 